\title{
INVESTIGACIONES
}

Las investigaciones reseñadas en esta primera parte del segundo número de la Revista, se realizan en la Oficina Sectorial de Planeación del Ministerio de Educación dentro del Proyecto de apoyo de la UNESCO Col. 76/003: "Administración, Planeación e Investigación Educativas".

Cada una de las investigaciones está bajo la responsabilidad de un grupo de Técnicos vinculados al Ministerio, con la Asesoría de Guillermo Briones, Experto de la UNESCO.

\section{ESTUDIO SOBRE LA EDUCACION PARA EL DESARROLLO RURAL}

\section{Planteamiento del problema}

Las condiciones de inferioridad en la educación rural colombiana se evidencian en una serie de factores tales como la cobertura del servicio ofrecido, calidad, condición socioeconómica de los maestros, materiales didácticos de apoyo, y aulas escolares. Estas situaciones se traducen en una baja eficiencia del sistema, según lo indican las altas tasas de deserción de la escuela rural, sin que la contribución de ese sistema al desarrollo económico social del país sea significativa.

Las políticas educativas en el sector rural han sido insuficientes para aumentar la escolarización y para producir mejoramientos reales de este servicio en el campo colombiano.

Debido a la ausencia de evaluaciones de los diversos programas del sector no es posible determinar la adecuación con la cual funcionan establecimientos de nivel medio de tipo vocacional, como ITA, INEM,

Núcleos Escolares, Escuelas Agropecuarias, etc.

Según las estadísticas del DANE, en 1973 , el $48.4 \%$ de la población rural entre siete y catorce años no estaba escolarizada, en comparación con el $22.5 \%$ en igual situación del sector urbano. La deserción escolar además, como se señalaba anteriormente, llega a niveles críticos: sólo el $8 \%$ de los matriculados en primero llega al quinto grado, mientras en las áreas urbanas la cifra alcanza el $67 \%$.

Estas consideraciones dan lugar a la prioridad asignada a un estudio integrado de la Educación para el Desarrollo Rural en el país, con el fin de proporcionar recomendaciones y elaborar proyectos concretos que permitan ir solucionando la grave situación en la cual se encuentra la educación en las zonas rurales. 


\section{Objetivos generales}

El estudio tiene como objetivo general, dotar al Gobierno Colombiano de un instrumento lo suficientemente analítico que le permita definir con precisión los fines, objetivos, currículo y demás especificaciones del sistema educativo en el medio rural, tendientes a lograr la expansión, el mejoramiento cualitativo y el fortalecimiento de la administración educativa rural.

\section{Objetivos específicos}

1. Descripción del sistema educativo a nivel nacional y departamental de acuerdo a los siguientes aspectos:

Orientación general, Administración, Operación, Servicios técnicos y de apoyo, Financiamiento.

2. Descripción de algunos indicadores socioeconómicos en relación con el sistema educativo.

3. Descripción y análisis de los programas y proyectos relacionados con la educación rural formal e informal, y de sus principales problemas administrativos, operativos y presupuéstales.

4. Elaborar conclusiones y recomendaciones tendientes a resolver los problemas y necesidades identificados en la educación rural.

5. Estimar el costo de las soluciones propuestas con el fin de apreciar la magnitud de los gastos e inversiones necesarios.

6. Identificar las necesidades de financiación, tanto para inversiones como para asistencia técnica por parte de entidades y organismos especializados nacionales e internacionales.

\section{Metodología}

Por ser el objetivo principal del estudio hacer un diagnóstico general de la situación actual del sistema educativo en el sector rural, se ha utilizado la información estadística necesaria para la estimación de la eficiencia del sistema y de las tendencias de desarrollo del mismo, que ha sido obtenida de fuentes secundarias: Planeación Nacional, DANE y División de Estadística y Sistemas del Ministerio de Educación.

Se ha obtenido también información, a través de paneles y entrevistas, con los funcionarios responsables, a nivel nacional, de los diferentes programas oficiales y privados dirigidos a esta área.

Finalmente, el equipo de investigadores ha realizado visitas a diferentes instituciones educativas del sector oficial e instalaciones de entidades privadas como Acción Cultural Popular y Federación de Cafeteros, entre otros. 


\section{Estado de la evaluación}

El estudio se encuentra en la etapa de redacción del informe final.

\section{EVALUACION DE LA EDUCACION BAJO CONTRATO CON LA IGLESIA CATOLICA}

\section{Planeamiento del problema}

La educación impartida en los territorios de misiones ha funcionado históricamente a cargo de la Iglesia Católica cuyo objetivo principal ha sido el de evangelizar las comunidades que habitan extensas áreas disgregadas y alejadas de los centros urbanos con deficientes medios de comunicación y transporte, baja densidad de población, precarios servicios asistenciales, de vivienda y condiciones climáticas insaludables, regiones, por lo demás, tradicionalmente descuidadas por el Estado.

La implantación de nuevas políticas educativas para estos territorios encuentra obstáculos dentro de la población tales como la imagen que ella tiene del servicio prestado por la Iglesia ya que para los habitantes la religión y la educación conforman una unidad, y cualquier modificación al interior de la estructura administrativa de la Iglesia puede significar la desprotección espiritual y el abandono del servicio educativo que ella les proporciona.

Ante la necesidad de asumir la responsabilidad de la administración de la educación en estos territorios el Gobierno Nacional ha adelantado algunas acciones:

En 1975 sustituye los antiguos convenios de misiones suscritos con la Santa Sede desde 1902, cuya última modificación data de 1953, al suscribir contratos con los Prelados cuya base legal es el Concordato firmado entre la República de Colombia y la Santa Sede (Ley 20 de 1974).

El Ministerio de Educación Nacional reglamenta a través de estos contratos los mecanismos y trámites legales que deberán seguir en lo sucesivo tanto la Iglesia como el Estado para la administración de la educación en los 17 territorios, que conservan la educación contratada.

Así mismo, se efectúa el primer traspaso de planteles de la administración de la Iglesia a manos del Estado.

La Comisión Mixta Permanente es el organismo rector de la administración de la educación por parte de la Iglesia y establece comunicación con el Ministerio de Educación Nacional para el cumplimiento de las funciones educativas.

\section{Objetivos generales}

El origen de este estudio se en-marca dentro de la necesidad del Ministerio de Educación de tener un conocimiento objetivo sobre el funcionamiento administrativo de la educación en estos territorios, que le proporcione elementos para tomar decisiones sobre cómo modificar y ampliar los actuales contratos, y la posibilidad de asumir total o parcialmente la administración de la educación. 